\title{
Association of Aortic Diameters with Coronary Artery Disease Severity and Albumin Excretion
}

\author{
Bülent Özdemir, ${ }^{1}$ Ali Emül,, ${ }^{2}$ Levent Özdemir, ${ }^{3}$ Saim Sağ, ${ }^{1}$ Murat Biçer, ${ }^{4}$ and Ali Aydınlar \\ ${ }^{1}$ Department of Cardiology, Uludă̆ University, Bursa, Turkey \\ ${ }^{2}$ Şevket Yilmaz Government Research and Training Hospital, Bursa, Turkey \\ ${ }^{3}$ Department of Public Health, Cumhuriyet University, Sivas, Turkey \\ ${ }^{4}$ Tıp Fakültesi Kalp, Damar Cerrahisi Anabilim Dal, Uludă̆ Üniversitesi, Görükle Kampüsü, Nilüfer, 16059 Bursa, Turkey
}

Correspondence should be addressed to Murat Biçer; mbicer23@yahoo.com

Received 17 February 2015; Revised 7 April 2015; Accepted 8 April 2015

Academic Editor: Juan A. Sanchis-Gimeno

Copyright (C) 2015 Bülent Özdemir et al. This is an open access article distributed under the Creative Commons Attribution License, which permits unrestricted use, distribution, and reproduction in any medium, provided the original work is properly cited.

\begin{abstract}
Introduction. Aortic diameters, aortic distensibility, microalbuminuria, coronary artery disease which are all together related to vascular aging are investigated in this paper. Methods. Eighty consecutive nondiabetic patients undergoing elective coronary angiography were enrolled into the study. Systolic and diastolic aortic diameters, aortic distensibility, CAD severity by angiogram with the use of Gensini scoring, and albumin excretion rates were determined. Results. Cases with CAD had significantly larger systolic (30,72 $\pm 3,21 \mathrm{~mm}$ versus $34,19 \pm 4,03 \mathrm{~mm}$ for cases without and with CAD, resp.) and diastolic aortic diameters measured $3 \mathrm{~cm}$ above aortic valve compared to patients without CAD (33,56 $\pm 4,07 \mathrm{~mm}$ versus $29,75 \pm 3,12 \mathrm{~mm})$. The systolic and diastolic diameters were significantly higher in albuminuria positive patients compared to albuminuria negative patients $(p=0.017$ and 0.008 , resp., for systolic and diastolic diameters). Conclusion. In conclusion aortic diameters are increased in patients with coronary artery disease and in patients with microalbuminuria. In CAD patients, systolic blood pressure, pulse pressure, aortic systolic and diastolic pressure, and albumin excretion rate were higher and aortic distensibility was lower.
\end{abstract}

\section{Introduction}

Aortic diameters are related to coronary artery disease. In a recent study, ascending aorta, aortic arch, distal thoracic aorta, and abdominal aorta diameters measured during autopsies of subjects that died of cardiovascular disease were significantly bigger than those of the subjects who died from other causes [1]. Aortic distensibility is a characteristic of the vessel wall and is related somewhat to contraction and dilation of the aorta. The definition can be equated as maximum change in area/(minimum area $\times$ pulse pressure). It can be measured anywhere through the course of the aorta. Many studies reported these changes during the cardiac cycle in both the ascending aorta and the descending aorta [2].

Coronary artery disease severity and extent determined by modified Gensini score were predicted by distal descending atheroma burden, ascending aorta distensibility, carotid flow mediated dilatation, and atheroma class in a magnetic resonance imaging study [3].
Association of aortic stiffness and microalbuminuria has been the focus of many studies [4-7]. In patients with hypertension, microalbuminuria and mildly reduced creatinine clearance were independently related to aortic stiffness which was calculated with carotid and femoral pulse [8]. Aortic distensibility is related to coronary flow reserve and coronary flow restoration with percutaneous coronary interventions improves aortic distensibility and coronary flow velocity reserve $[9,10]$.

The rate of having coronary heart disease among renal failure patients is quite high [11]. The same risk factors may affect both renal and cardiac functions and vasculature. End stage renal disease patients' coronary artery disease risk is 10 times higher compared to high-risk patients of Framingham's study [12]. Microalbuminuria was used as a marker for diabetic nephropathy and lately for cardiovascular morbidity and mortality $[13,14]$. Also the association of the severity of coronary artery disease with microalbuminuria presence 


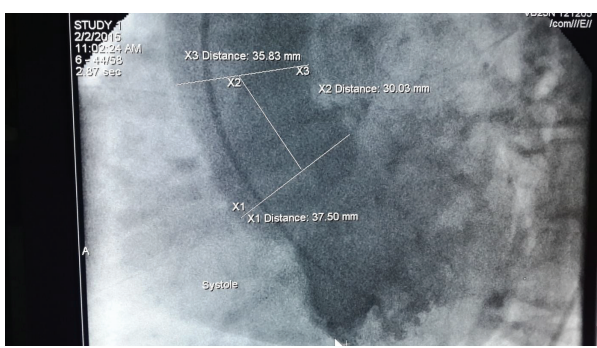

(a)

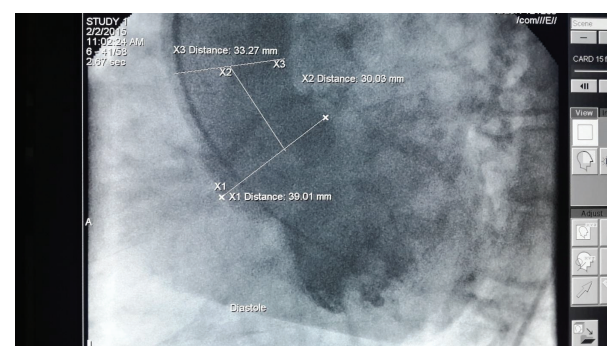

(b)

Figure 1: Aortic diameters are measured $3 \mathrm{~cm}$ above the aortic orifice. The illustrations cover systole (a) and diastole (b).

was reported in another study by Khan et al. [15]. In a study that utilised coronary computed tomography angiography, association of presence, extent, and severity of coronary artery disease in asymptomatic patients with type $2 \mathrm{DM}$ with microalbuminuria was investigated. In that study patients with microalbuminuria had more severe coronary lesions. Microalbuminuria clearly predicted high coronary artery disease risk and worse clinical outcomes [16].

\section{Materials and Methods}

Eighty consecutive patients undergoing elective coronary angiography in the Cardiology Department of the Applied Research Centre for Health of Uludağ University were enrolled into the study. The angiograms were performed with use of Siemens cardiac catheterization unit in the Hemodynamics Laboratory of the Cardiology Department. This was a prospective study in which the aortic diameters and aortic elasticity were determined along with the Gensini score that allowed assessing the severity of CAD [17]. A Gensini score greater than 20 was defined as a high Gensini score.

Systolic and diastolic diameters were measured $3 \mathrm{~cm}$ above the aortic valve (in $\mathrm{cm}$ ) (Figures 1(a) and 1(b)). Aortic distensibility was calculated as follows: $2 \times$ (change in aortic diameter)/(diastolic aortic diameter) $\times($ change in aortic pressure), where change in aortic diameter equals systolic minus diastolic aortic diameter, and change in aortic pressure equals systolic minus diastolic aortic pressure [18, 19]. Aortic pulse pressure was calculated as systolic aortic pressure minus diastolic aortic pressure. Hypertension was defined as having blood pressure greater than or equal to $140 / 90 \mathrm{mmHg}$ or being on treatment.

The coronary angiograms were evaluated. Chi-Square Test was used for classified variables and Mann-Whitney $U$ test was used for comparison of two groups. The statistical analyses were performed by use of SPSS data Manager Software system. Statistical significance was assumed in case of a $p$ value $<0.05$. The results are expressed as mean \pm standard deviation.

The patients were evaluated by dividing into two groups according to having $\mathrm{CAD}$ and also having albuminuria. The comparisons were made by categorising the cases as having no $\mathrm{CAD}$, mild $\mathrm{CAD}$, and severe coronary artery diseases. Also
TABLE 1: Characteristics of the patients.

\begin{tabular}{|c|c|c|c|c|c|}
\hline & Male & $\%$ & Female & $\%$ & Total \\
\hline \multirow[t]{2}{*}{ Gender } & 49 & 61,3 & 31 & 38,7 & 80 \\
\hline & Present & $\%$ & Absent & $\%$ & \\
\hline Obesity & 21 & 26,3 & 59 & 73,7 & 80 \\
\hline Smoking & 38 & 47,5 & 42 & 52,5 & 80 \\
\hline Hypertension & 48 & 60,0 & 32 & 40,0 & 80 \\
\hline Dyslipidemia & 37 & 46,3 & 43 & 53,8 & 80 \\
\hline Age (years) & \multicolumn{5}{|c|}{$59,9 \pm 10,0$} \\
\hline Height $(\mathrm{cm})$ & \multicolumn{5}{|c|}{$165,8 \pm 6,9$} \\
\hline Weight (kg) & \multicolumn{5}{|c|}{$75,9 \pm 9,5$} \\
\hline $\mathrm{BMI}\left(\mathrm{kg} / \mathrm{m}^{2}\right)$ & \multicolumn{5}{|c|}{$27,6 \pm 3,9$} \\
\hline \multicolumn{6}{|c|}{ Serum levels of biochemical markers } \\
\hline Total cholesterol (mg/dL) & \multicolumn{5}{|c|}{$183,4 \pm 47,9$} \\
\hline LDL cholesterol (mg/dL) & \multicolumn{5}{|c|}{$113,5 \pm 38,3$} \\
\hline HDL cholesterol (mg/dL) & \multicolumn{5}{|c|}{$44,0 \pm 13,6$} \\
\hline Triglyceride (mg/dL) & \multicolumn{5}{|c|}{$140,7 \pm 68,6$} \\
\hline Urea $(\mathrm{mg} / \mathrm{dL})$ & \multicolumn{5}{|c|}{$36,9 \pm 12,8$} \\
\hline Creatinine (mg/dL) & \multicolumn{5}{|c|}{$0,98 \pm 0,23$} \\
\hline Uric acid (mg/dL) & \multicolumn{5}{|c|}{$5,58 \pm 1,82$} \\
\hline Haemoglobin $(\mathrm{g} / \mathrm{dL})$ & \multicolumn{5}{|c|}{$12,84 \pm 1,96$} \\
\hline \multicolumn{6}{|c|}{ Aortic measurements } \\
\hline Systolic blood pressure $(\mathrm{mmHg})$ & \multicolumn{5}{|c|}{$124,7 \pm 14,6$} \\
\hline $\begin{array}{l}\text { Diastolic blood pressure } \\
(\mathrm{mmHg})\end{array}$ & \multicolumn{5}{|c|}{$74,9 \pm 8,9$} \\
\hline Pulse pressure $(\mathrm{mmHg})$ & \multicolumn{5}{|c|}{$49,8 \pm 10,8$} \\
\hline Mean aortic pressure (mmHg) & \multicolumn{5}{|c|}{$100,1 \pm 14,0$} \\
\hline Aortic distensibility & \multicolumn{5}{|c|}{$2,88 \pm 2,21$} \\
\hline Aortic systolic diameter (mm) & \multicolumn{5}{|c|}{$33,2 \pm 4,11$} \\
\hline Aortic diastolic diameter ( $\mathrm{mm})$ & \multicolumn{5}{|c|}{$32,5 \pm 4,1$} \\
\hline
\end{tabular}

comparisons were made according to having no, moderate, and severe albumin excretion rates.

\section{Results and Discussion}

The characteristics of the patients are given in Table 1. When the cases were divided into two according to having CAD 
TABLE 2: Aortic measurement and albuminuria levels according to CAD presence.

\begin{tabular}{|c|c|c|c|c|c|c|c|}
\hline & \multicolumn{3}{|c|}{ Coronary artery disease negative $(n=21)$} & \multicolumn{3}{|c|}{ Coronary artery disease positive $(n=59)$} & \multirow{2}{*}{$p$ value } \\
\hline & Median & $(\min -\max )$ & IQR & Median & $(\min -\max )$ & IQR & \\
\hline${ }^{*}$ Systolic blood pressure & 117 & 95-135 & 19 & 127 & $97-184$ & 19 & 0,003 \\
\hline${ }^{*}$ Diastolic blood pressure & 75 & $64-94$ & 11,50 & 74 & $57-98$ & 12 & 0,45 \\
\hline${ }^{*}$ Pulse pressure & 43 & $26-65$ & 13 & 52 & $32-78$ & 13 & 0,003 \\
\hline${ }^{*}$ Mean aortic pressure & 100 & $70-120$ & 12 & 100 & $73-133$ & 17 & 0,12 \\
\hline Aortic distensibility & 3,02 & $0,99-14,40$ & 3,80 & 2,27 & $0,32-11,20$ & 1,60 & 0,013 \\
\hline Aortic systolic diameter (mm) & 30,61 & $25,81-38,10$ & 5,41 & 33,52 & $27,32-48,16$ & 6,30 & $<0,001$ \\
\hline Aortic diastolic diameter (mm) & 29,47 & $25,46-36,83$ & 5,62 & 33,02 & $26,73-47,06$ & 6,46 & $<0,001$ \\
\hline Proteinuria level & 12 & $4-256$ & 125 & 170 & $5-1931$ & 161 & $<0,001$ \\
\hline
\end{tabular}

${ }^{*} \mathrm{mmHg}$; IQR: interquartile range.

TABLE 3: Comparison of the groups according to presence of albuminuria.

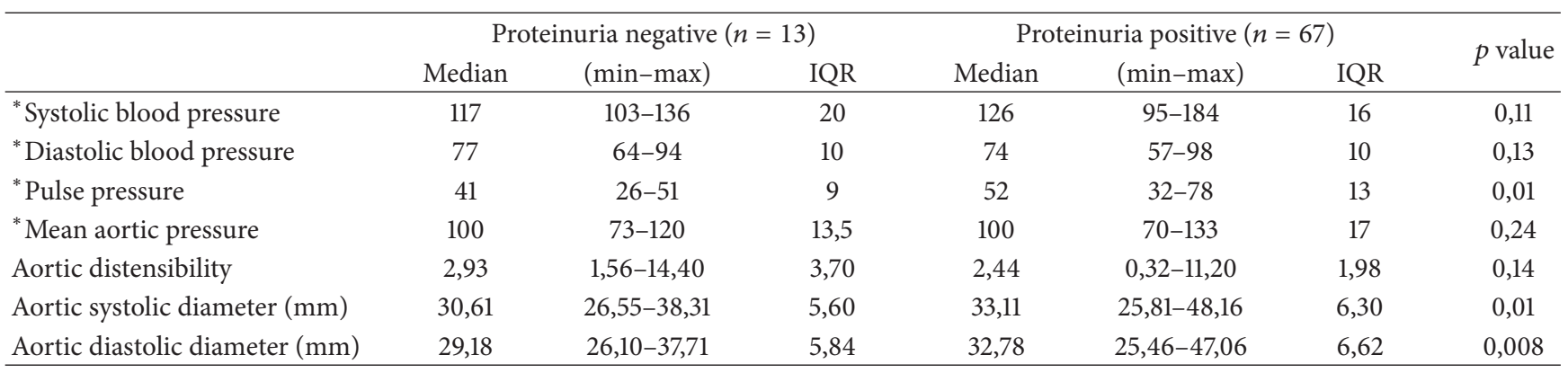

${ }^{*} \mathrm{mmHg}$; IQR: interquartile range.

or not having CAD, aortic dimensions both in systole and diastole were significantly different. When systolic aortic diameter was compared, cases with CAD had significantly larger systolic aortic diameter $(30,72 \pm 3,21 \mathrm{~mm}$ versus $34,19 \pm 4,03 \mathrm{~mm}$ for cases without and with CAD, resp.). Also the same was true for the aortic diastolic diameters measured $3 \mathrm{~cm}$ above aortic valve with significantly bigger aortic diameter for the CAD patients compared to patients without $\operatorname{CAD}(33,56 \pm 4,07 \mathrm{~mm}$ versus $29,75 \pm 3,12 \mathrm{~mm})$. The aortic distensibility showing the elastic properties of the aorta was significantly smaller in CAD patients $(p=0.013)$ (Table 2). Also in CAD patients the systolic blood pressure was significantly higher compared to cases without CAD $(127,4 \pm 14,7 \mathrm{mmHg}$ versus $117,1 \pm 11,9 \mathrm{mmHg} ; p=0.03)$. However the diastolic blood pressure failed to show a significant difference. Pulse pressure and proteinuria level also were significantly higher in CAD patients (Table 2 ).

In Table 3 the comparison of the albuminuria positive and albuminuria negative groups is given. Systolic pressure and diastolic pressure were indifferent in albuminuria positive and albuminuria negative patients. Pulse pressure was significantly higher in albuminuria positive patients. Albuminuria presence did not cause significant difference in aortic distensibility among groups. But both the systolic and diastolic diameters were significantly higher in albuminuria positive patients compared to albuminuria negative patients ( $p=0.017$ and 0.008 , resp., for systolic and diastolic diameters).
Grouping the cases by $<50$ years of age and $\geq 50$ years of age showed that rate of presence of hypertension was significantly higher in the cases belonging to the latter group ( $25 \%$ versus $66.2 \%$, resp., with a $p$ value $<0.05$ ). However, rate of presence of albuminuria was not significantly different between the groups of cases with $<50$ and $\geq 50$ years of age. Also grouping of cases according to a cut-off of age of 50 years showed that rate of having CAD in the cases with age of 50 years or older was significantly higher compared to others. Also only $3,1 \%$ of cases with significant coronary artery disease according to Gensini scoring were younger than 50 years of age. A cut-off value of $50 \mathrm{mmHg}$ for pulse pressure significantly showed that a higher level of albumin excretion was the case for cases which had a pulse pressure of $50 \mathrm{mmHg}$ or higher compared to others $(p<0.05)$.

When cases with CAD were compared to cases without $\mathrm{CAD}$ the mean albumin excretion rate was significantly lower $(p<0.05)$. However, albumin excretion rate did not differ between cases with mild CAD and cases with severe CAD patients $(p>0.05)$. When patients were grouped into having microalbuminuria or having CAD and compared accordingly, presence of albuminuria predicted presence of CAD (Figure 2).

Presence of CAD is significantly related to aortic diameters [1]. In the study by Milan et al. all the studied segments of aorta were significantly larger in the group with cardiovascular disease. A tendency to decrease in the size of aorta from ascending to abdominal aorta segments was 


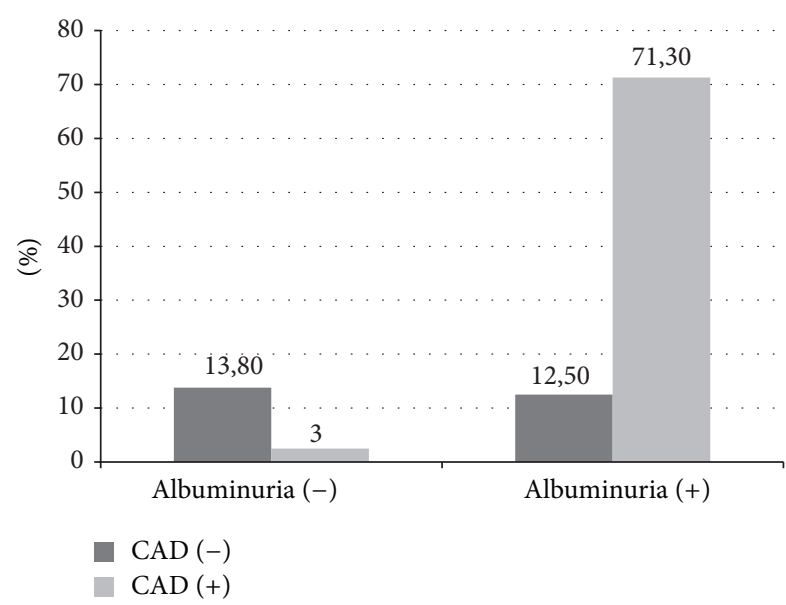

FIgURe 2: Percent distribution of all the cases $(n=80)$ according to presence of CAD and albuminuria. Albuminuria presence was significantly associated with presence of coronary artery disease $(p<0,001)$.

also noted in the study that involved autopsy subjects. These results were consistent with the results in this paper. In cases with hypertension dilatation of the ascending aorta is more common [20]. In a study by Giannattasio et al., arterial distensibility in patients with type I (insulin-dependent) diabetes mellitus without macrovascular complication was evaluated. In their study arterial distensibility was lower in a consistent manner compared to the control group. Noting increased radial and carotid artery thicknesses, they stated that the changes were more pronounced in patients with microalbuminuria, retinopathy, or neuropathy. Interestingly, the arterial wall stiffening and thickening was seen in the absence of diabetic complications, suggesting those being an early marker of vascular damage [21]. Arterial stiffness also is associated with premature coronary artery disease occurrence [22]. Being consistent with the result of our study there are reports saying that in CAD patients the aortic distensibility is markedly reduced. Ascending aorta stiffness index is associated with coronary artery disease in hypertensive patients [23].

In our study albuminuria did not affect aortic distensibility but aortic diameters were significantly higher in the albuminuria positive patients. However, in a study by Cuspidi et al. microalbuminuria was not associated with abdominal aortic diameter [24]. Also endothelial dysfunction is associated with microalbuminuria as reported 2 decades ago by Pedrinelli et al. In their study von Willebrand Factor antigen concentrations that showed presence of endothelial dysfunction were higher in hypertensive patients with microalbuminuria compared to other groups [25]. Coronary artery disease is considered as an important complication of type 2 diabetes mellitus. Guo et al. evaluated the correlation of urinary albumin excretion rate with the coronary heart disease severity and incidence, in patients with type 2 diabetes mellitus, aged 60 years or older. They reported that urinary albumin excretion rate was independently correlated with coronary artery disease in patients with type 2 diabetes mellitus. Also the severity of coronary artery disease determined with Gensini scoring was independently associated with urinary albumin excretion rate [26]. However in our study the microalbuminuria did not differ between mild and severe coronary artery disease patients according to Gensini scoring. That makes us think that microalbuminuria helps us to detect presence of CAD but fails to show the extent of the disease. But we have to admit that these subjects need further investigation.

\section{Conclusion}

In conclusion aortic diameters are increased in patients with coronary artery disease and in patients with microalbuminuria. In CAD patients, systolic blood pressure, pulse pressure, aortic systolic and diastolic pressure, and albumin excretion rate were higher and aortic distensibility was lower.

\section{Conflict of Interests}

No conflict of interests is declared by the authors.

\section{References}

[1] O. C. Mirea, A. A. AncuŢa, M. S. Şerbănescu et al., "Analysis of aortic size in subjects died due to cardiovascular and noncardiovascular events: a necropsy study," Romanian Journal of Morphology and Embryology, vol. 55, no. 3, supplement, pp. 1105-1109, 2014.

[2] M. Ganten, U. Krautter, W. Hosch et al., "Age related changes of human aortic distensibility: evaluation with ECG-gated CT," European Radiology, vol. 17, no. 3, pp. 701-708, 2007.

[3] I. Kylintireas, C. Shirodaria, J. M. S. Lee et al., "Multimodal cardiovascular magnetic resonance quantifies regional variation in vascular structure and function in patients with coronary artery disease: relationships with coronary disease severity," Journal of Cardiovascular Magnetic Resonance, vol. 13, article 61, 2011.

[4] G. Mulè, S. Cottone, A. Vadalà et al., "Relationship between albumin excretion rate and aortic stiffness in untreated essential hypertensive patients," Journal of Internal Medicine, vol. 256, no. 1, pp. 22-29, 2004.

[5] E. Ishimura, H. Taniwaki, T. Tsuchida et al., "Urinary albumin excretion associated with arteria wall stiffness rather than thickness in type 2 diabetic patients," Journal of Nephrology, vol. 20, no. 2, pp. 204-211, 2007.

[6] D. I. Shin, K.-B. Seung, H. E. Yoon et al., "Microalbuminuria is independently associated with arterial stiffness and vascular inflammation but not with carotid intima-media thickness in patients with newly diagnosed type 2 diabetes or essential hypertension," Journal of Korean Medical Science, vol. 28, no. 2, pp. 252-260, 2013.

[7] M. M. H. Hermans, R. Henry, J. M. Dekker et al., "Estimated glomerular filtration rate and urinary albumin excretion are independently associated with greater arterial stiffness: the Hoorn study," Journal of the American Society of Nephrology, vol. 18, no. 6, pp. 1942-1952, 2007.

[8] G. Mulè, S. Cottone, P. Cusimano et al., "Unfavourable interaction of microalbuminuria and mildly reduced creatinine clearance on aortic stiffness in essential hypertension," International Journal of Cardiology, vol. 145, no. 2, pp. 372-375, 2010. 
[9] A. Nemes, M. Csanády, and T. Forster, "Does increased aortic stiffness predict reduced coronary flow velocity reserve in patients with suspected coronary artery disease?" Acta Physiologica Hungarica, vol. 99, no. 3, pp. 271-278, 2012.

[10] A. Nemes, I. Ungi, M. Csanády, and T. Forster, "Simultaneous improvement in aortic distensibility and coronary flow velocity reserve after successful coronary interventions," Echocardiography, vol. 27, no. 3, pp. 311-316, 2010.

[11] P. A. McCullough, "Coronary artery disease," Clinical Journal of the American Society of Nephrology, vol. 2, no. 3, pp. 611-616, 2007.

[12] P. A. McCullough, "Cardiorenal risk: an important clinical intersection," Reviews in Cardiovascular Medicine, vol. 3, no. 2, pp. 71-76, 2002.

[13] C. E. Mogensen, "Microalbuminuria predicts clinical proteinuria and early mortality in maturity-onset diabetes," The New England Journal of Medicine, vol. 310, no. 6, pp. 356-360, 1984.

[14] G. Mancia, G. de Backer, A. Dominiczak et al., "ESH/ESC 2007 Guidelines for the management of arterial hypertension," Revista Española de Cardiología, vol. 60, no. 9, pp. 968.e1-994.el, 2007.

[15] K. N. Khan, M. H. Khan, and M. Z. Haque, "Correlation between microalbuminuria with complexity of coronary artery disease in diabetic patients," Mymensingh Medical Journal, vol. 22, no. 2, pp. 353-357, 2013.

[16] J. Kim, B.-H. Hwang, I. J. Choi et al., "A prospective twocenter study on the associations between microalbuminuria, coronary atherosclerosis and long-term clinical outcome in asymptomatic patients with type 2 diabetes mellitus: evaluation by coronary CT angiography," The International Journal of Cardiovascular Imaging, vol. 31, no. 1, pp. 193-203, 2015.

[17] G. G. Gensini, "A more meaningful scoring system for determining the severity of coronary heart disease," The American Journal of Cardiology, vol. 51, no. 3, article 606, 1983.

[18] B. Özdemir, M. Biçer, L. Özdemir et al., "Aortic distensibility and coronary artery bypass graft patency," Journal of Cardiothoracic Surgery, vol. 4, no. 1, article 14, 2009.

[19] C. Stefanadis, C. Stratos, H. Boudoulas, C. Kourouklis, and P. Toutouzas, "Distensibility of the ascending aorta: comparison of invasive and non-invasive techniques in healthy men and in men with coronary artery disease," European Heart Journal, vol. 11, no. 11, pp. 990-996, 1990.

[20] A. Milan, F. Tosello, D. Naso et al., "Ascending aortic dilatation, arterial stiffness and cardiac organ damage in essential hypertension," Journal of Hypertension, vol. 31, no. 1, pp. 109-116, 2013.

[21] C. Giannattasio, M. Failla, A. Piperno et al., "Early impairment of large artery structure and function in Type I diabetes mellitus," Diabetologia, vol. 42, no. 8, pp. 987-994, 1999.

[22] B. Güngör, H. Yilmaz, A. Ekmekçi et al., "Aortic stiffness is increased in patients with premature coronary artery disease: a tissue Doppler imaging study," Journal of Cardiology, vol. 63, no. 3, pp. 223-229, 2014.

[23] Q. Lu and H. Liu, "Correlation of ascending aorta elasticity and the severity of coronary artery stenosis in hypertensive patients with coronary heart disease assessed by M-mode and tissue doppler echocardiography," Cell Biochemistry and Biophysics, vol. 71, no. 2, pp. 785-788, 2015.

[24] C. Cuspidi, S. Meani, F. Negri, C. Sala, and G. Mancia, "Left ventricular hypertrophy and abdominal aorta size in essential hypertension," Journal of Hypertension, vol. 29, no. 6, pp. 12131219, 2011.
[25] R. Pedrinelli, O. Giampietro, F. Carmassi et al., "Microalbuminuria and endothelial dysfunction in essential hypertension," The Lancet, vol. 344, no. 8914, pp. 14-18, 1994.

[26] L.-X. Guo, J. Ma, Y. Cheng, L.-N. Zhang, and M. Li, "Urinary albumin excretion rate is correlated with severity of coronary artery disease in elderly type 2 diabetic patients," Chinese Medical Journal, vol. 125, no. 23, pp. 4181-4184, 2012. 

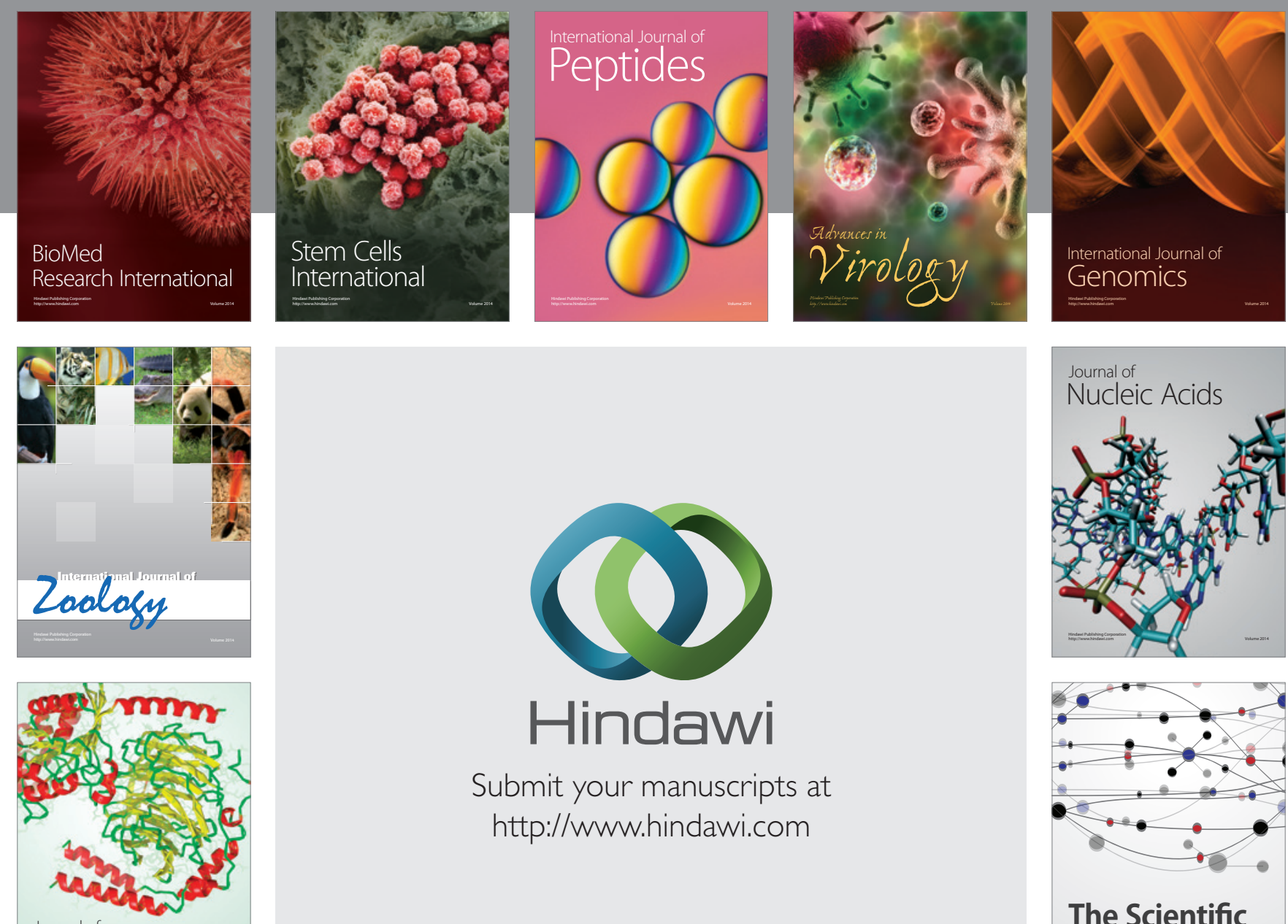

Submit your manuscripts at

http://www.hindawi.com

Journal of
Signal Transduction
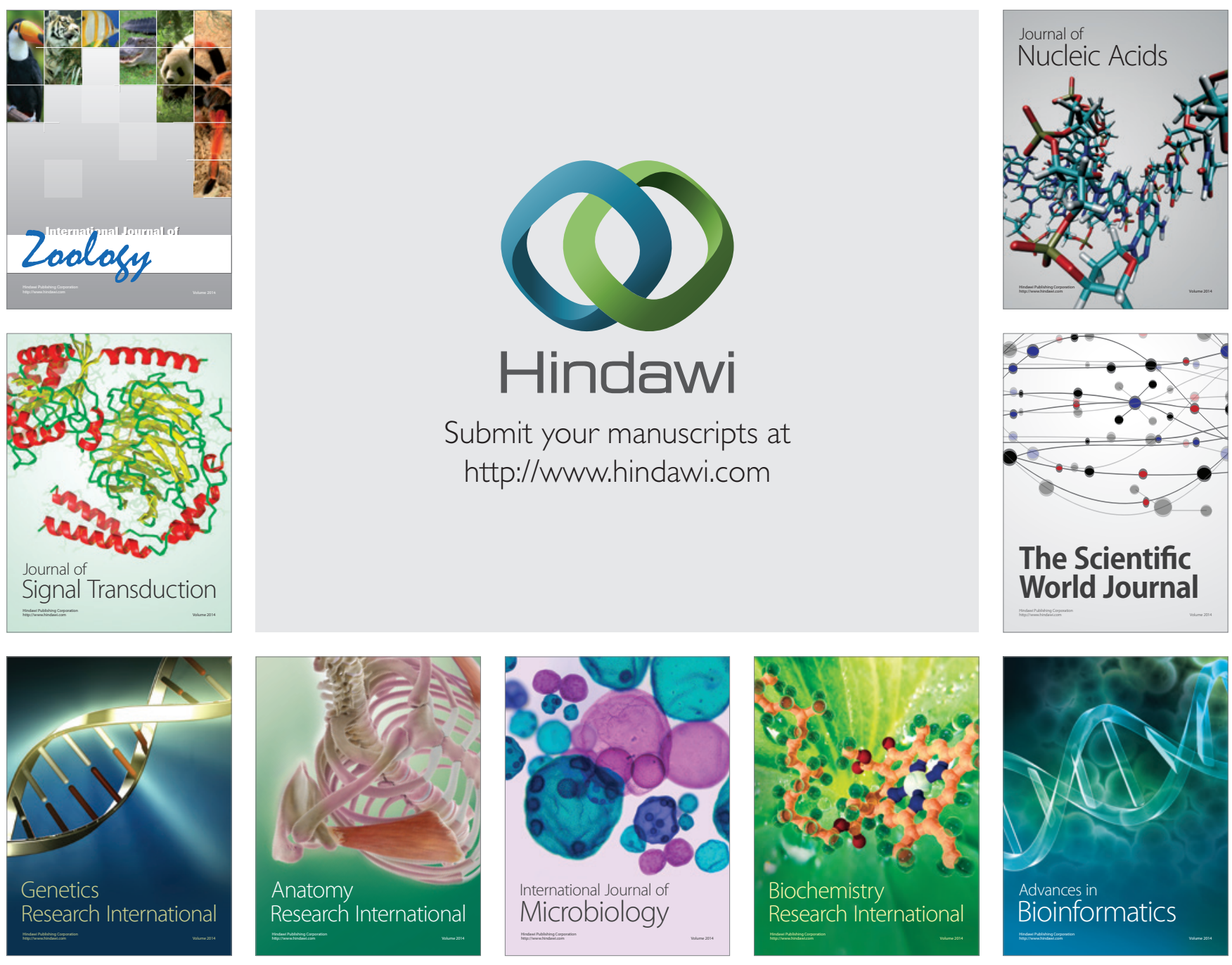

The Scientific World Journal
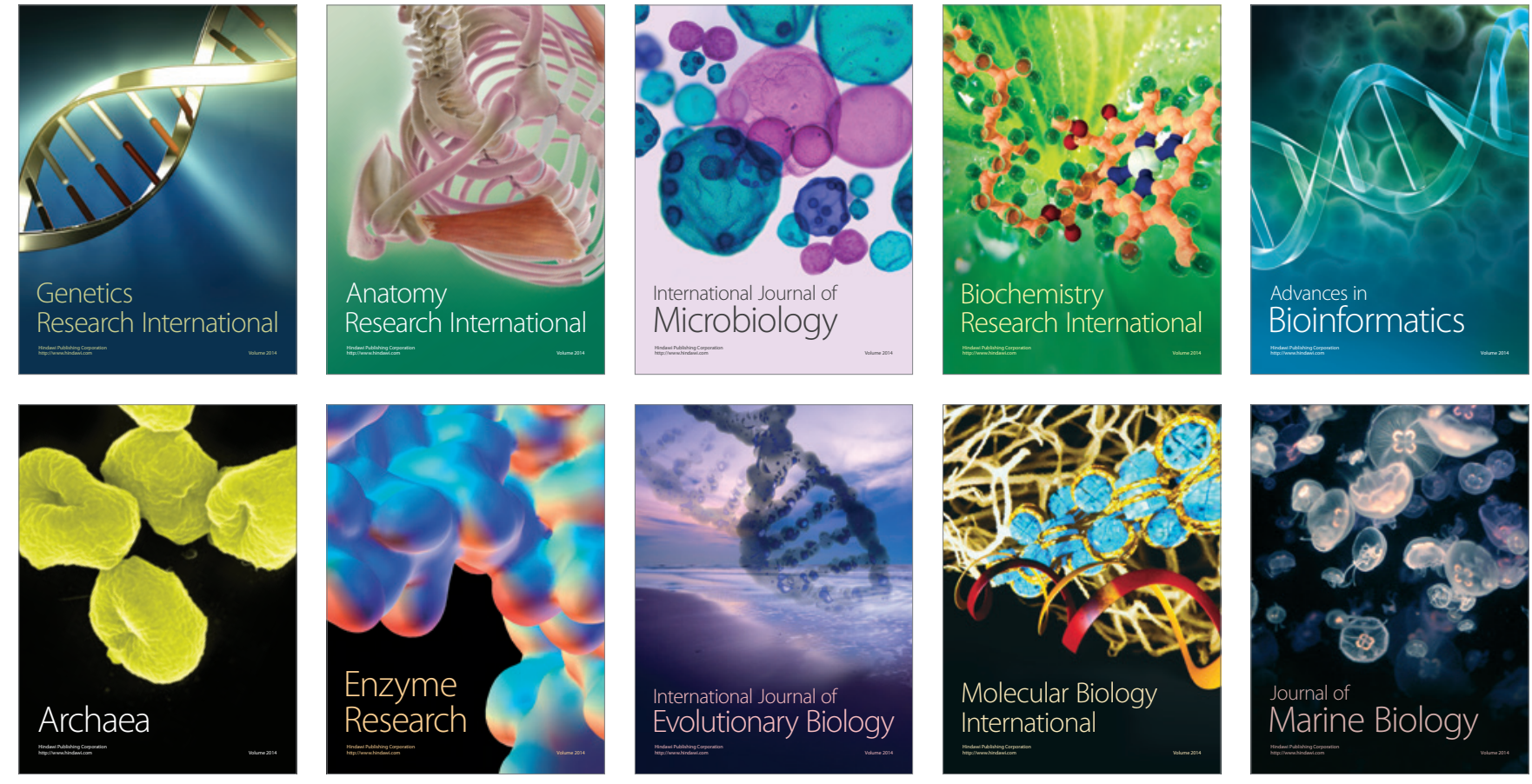